\section{Case Reports in Acute Medicine}

\title{
Silent Acute Renal Impairment after Low-dose Paraquat Ingestion
}

\author{
Hiroshi Ito \\ Department of Internal Medicine, Ibaraki Prefectural Central Hospital, Kasama, Japan
}

\section{Keywords}

Paraquat · Acute kidney injury · Creatinine

\begin{abstract}
Paraquat poisoning causes fatal multi-organ failure soon after ingestion. Here we report a case of paraquat poisoning presenting acute kidney injury without any preceding signs and symptoms other than nausea and vomiting. A 77-year-old man was admitted to our hospital because of paraquat ingestion and received fluid resuscitation until the negative conversion of urine paraquat on day 4 . Serum creatinine abnormality emerged on the same day, which improved gradually without any specific intervention. Paraquat poisoning can cause silent acute renal impairment. Abundant fluid resuscitation after renal impairment is not essential provided that sufficient fluid is administered beforehand. Repeated screening for renal impairment and sufficient fluid resuscitation are important in the early phase of low-dose paraquat poisoning.

(C) 2019 The Author(s)

Published by S. Karger AG, Basel
\end{abstract}

\section{Introduction}

Paraquat, a rapidly-acting herbicide, is a leading cause of fatal poisoning when ingested [1]. Paraquat poisoning causes multi-organ failure over a period of hours to days, such as acute kidney injury (AKI), metabolic acidosis, and acute respiratory distress syndrome. The management includes fluid resuscitation, antioxidant therapy, hemoperfusion, and hemodialysis 
[2]. However, there are no widely accepted treatment strategies of paraquat poisoning because of its high mortality. We here report a case of paraquat poisoning presenting AKI without respiratory failure, that is, silent acute renal impairment managed by fluid resuscitation in advance and vitamin $\mathrm{C}$ supplementation.

\section{Case Presentation}

A 77-year-old man was brought to our emergency department $6 \mathrm{~h}$ after ingestion of paraquat in a suicide attempt. He had hypertension and rheumatoid arthritis. On arrival, his complaint was only nausea and vomiting. His consciousness level was about E4V5M6 on the Glasgow Coma Scale. Blood pressure was 130/68 mm Hg, heart rate was 85/min, oxygen saturation was $95 \%$ at room air, body temperature was $37.0^{\circ} \mathrm{C}$, and his pupils were normal in size. Initial arterial blood gas showed mild alkalemia: $\mathrm{pH} 7.497$, partial pressure of oxygen $71.0 \mathrm{~mm}$ $\mathrm{Hg}$, partial pressure of carbon dioxide $37.1 \mathrm{~mm} \mathrm{Hg}$, bicarbonate $28.7 \mathrm{mEq} / \mathrm{L}$, and lactate 0.9 $\mathrm{mmol} / \mathrm{L}$. Laboratory data showed the following: aspartate aminotransferase $59 \mathrm{U} / \mathrm{L}$, alanine aminotransferase $42 \mathrm{U} / \mathrm{L}$, lactate dehydrogenase $217 \mathrm{U} / \mathrm{L}$, sodium $139 \mathrm{mEq} / \mathrm{L}$, potassium 3.7 $\mathrm{mEq} / \mathrm{L}$, chloride $102 \mathrm{mEq} / \mathrm{L}$, blood urea nitrogen $21 \mathrm{mg} / \mathrm{dL}$, and creatinine $0.67 \mathrm{mg} / \mathrm{dL}$. Drug screening test of urine sample was positive only for paraquat. Electrocardiogram and chest X-ray showed no remarkable findings.

On admission, fluid resuscitation therapy was initiated, and $25 \mathrm{~g}$ of activated carbon was administrated orally. With the use of a laxative, he had bluish-green watery diarrhea three times at night. Although urine paraquat was positive on day 2 , his nausea and vomiting were relieved without emergence of other signs and symptoms. Fluid resuscitation was continued. Oral intake and vitamin $C$ supplementation were initiated. Urine output was below 0.5 $\mathrm{mL} / \mathrm{kg} / \mathrm{h}$ on day 2 , which exceeded $1.0 \mathrm{~mL} / \mathrm{kg} / \mathrm{h}$ on day 3 . Urine paraquat became negative on day 4 , but the laboratory data showed serum creatinine $4.11 \mathrm{mg} / \mathrm{dL}$, which indicated acute renal injury. Fluid resuscitation was tapered off because of the negative conversion of urine paraquat. In addition, because the urine output was slightly decreased, furosemide was administrated in order to promote a diuretic effect. Serum creatinine level was $4.91 \mathrm{mg} / \mathrm{dL}$ on day 5 , and $3.10 \mathrm{mg} / \mathrm{dL}$ on day 6 . Because of the improvement of renal function and the emergence of nonpitting edema of the lower extremities, fluid resuscitation was stopped on day 6. Furosemide was also stopped on the same day because of the constant urine output over 1.0 $\mathrm{mL} / \mathrm{kg} / \mathrm{h}$. The renal function was gradually improved, and serum creatinine level was 1.27 $\mathrm{mg} / \mathrm{dL}$ on day 15. The patient was discharged on day 17. During admission, there were no signs and symptoms of lung injury. In hindsight, the serum paraquat level was $0.3 \mu \mathrm{g} / \mathrm{mL} 6 \mathrm{~h}$ after ingestion, and less than $0.1 \mu \mathrm{g} / \mathrm{mL} 24 \mathrm{~h}$ after ingestion. The transition of serum creatinine is shown in Figure 1.

\section{Discussion/Conclusion}

Two important clinical issues are shown in this case. Low-dose paraquat poisoning can cause AKI suddenly without any specific preceding symptoms. Abundant fluid resuscitation is not essential after the occurrence of AKI if sufficient fluid is administered in advance.

First, low-dose paraquat can cause AKI suddenly. Although less well studied, a previous study has shown that there are no significant differences in serum paraquat levels between patients with and without AKI after paraquat ingestion [3]. Considering that serum paraquat 
levels are predictive of the mortality of patients [4, 5], paraquat poisoning can cause AKI without any signs and symptoms, that is to say, silent acute renal impairment. One possible explanation of isolated renal impairment without respiratory involvement is that the ingested paraquat was eliminated primarily by the kidney without undergoing significant metabolism, where the concentration of paraquat might have reached a high level [6]. Because our patient remained in a stable physical condition after admission, frequently repeated creatinine screening was the only way to detect his acute renal impairment.

Second, abundant fluid resuscitation is not essential after the occurrence of AKI if sufficient fluid is administered in advance. Although fluid resuscitation was tapered off because of the negative urine paraquat shortly after the emergence of serum creatinine abnormality, the renal function improved gradually in this case. One possible explanation is a serum creatinine lag behind acute renal injury. Substantial rises in serum creatinine are often not witnessed until 48-72 $\mathrm{h}$ after the initial insult to the kidney [7], which has recently triggered the development of early biomarkers of AKI [8]. Renal injury in this case might have been present soon after the paraquat ingestion, and the early fluid administration might have been helpful in improving renal hydration and eliminating paraquat in the urine at an optimal timing, although we did not measure new AKI biomarkers such as liver-type fatty acid-binding protein or neutrophil gelatinase-associated lipocalin during the AKI event.

In conclusion, low-dose paraquat poisoning can cause silent acute renal impairment. Abundant fluid resuscitation is not essential after the emergence of serum creatinine abnormality on condition that sufficient fluid resuscitation is done in advance. Further reports should be accumulated, measuring new AKI biomarkers, to determine whether acute renal injury may occur soon after paraquat ingestion.

\section{Acknowledgments}

The author is grateful to K. Nagatomo and R. Sekine for carefully proofreading the manuscript.

\section{Statement of Ethics}

The author has no ethical conflicts to disclose. Written informed consent to publish this case report was received from the patient.

\section{Disclosure Statement}

The author has no conflicts of interest to declare.

\section{Funding Sources}

The author has no funding sources to disclose. 
Ito: Silent Acute Renal Impairment after Low-dose Paraquat Ingestion

\section{References}

1 Fairshter RD, Wilson AF. Paraquat poisoning: manifestations and therapy. Am J Med. 1975 Dec;59(6):751-3.

2 Park S, Lee S, Park S, Gil H, Lee E, Yang J, et al. Concurrent Hemoperfusion and Hemodialysis in Patients with Acute Pesticide Intoxication. Blood Purif. 2016;42(4):329-36.

3 Kim SJ, Gil HW, Yang JO, Lee EY, Hong SY. The clinical features of acute kidney injury in patients with acute paraquat intoxication. Nephrol Dial Transplant. 2009 Apr;24(4):1226-32.

4 Proudfoot AT, Stewart MS, Levitt T, Widdop B. Paraquat poisoning: significance of plasma-paraquat concentrations. Lancet. 1979 Aug;2(8138):330-2.

5 Senarathna L, Eddleston M, Wilks MF, Woollen BH, Tomenson JA, Roberts DM, et al. Prediction of outcome after paraquat poisoning by measurement of the plasma paraquat concentration. QJM. 2009 Apr;102(4):251-9.

6 Houzé P, Baud FJ, Mouy R, Bismuth C, Bourdon R, Scherrmann JM. Toxicokinetics of paraquat in humans. Hum Exp Toxicol. 1990 Jan;9(1):5-12.

7 Mehta RL, Chertow GM. Acute renal failure definitions and classification: time for change? J Am Soc Nephrol. 2003 Aug;14(8):2178-87.

8 Coca SG, Yalavarthy R, Concato J, Parikh CR. Biomarkers for the diagnosis and risk stratification of acute kidney injury: a systematic review. Kidney Int. 2008 May;73(9):1008-16.

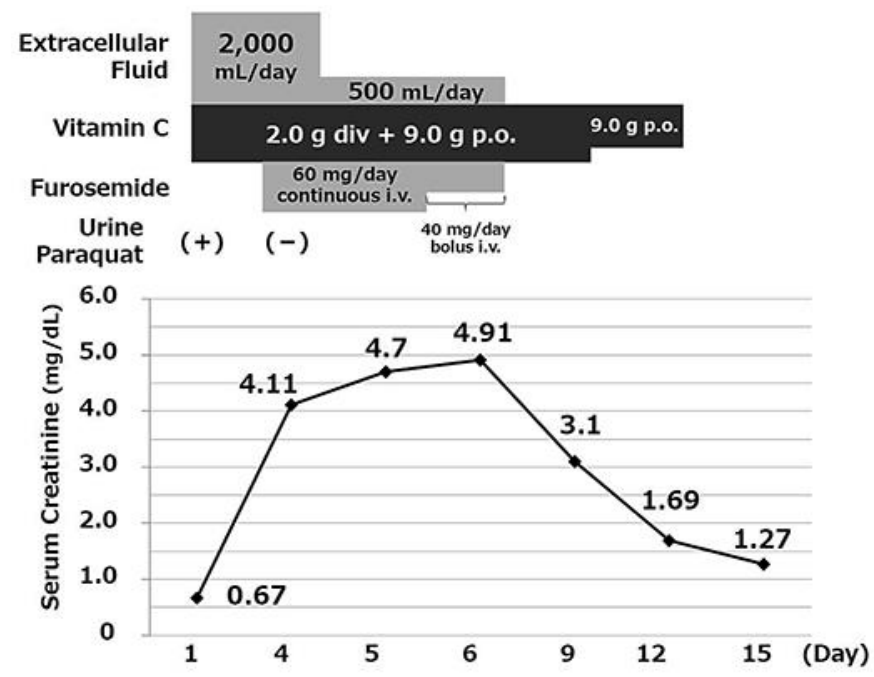

Fig. 1. Transition of serum creatinine. 